\title{
Multidisciplinary approach to minimally invasive lung segmentectomy
}

\author{
Matthieu Sarsam ${ }^{1}$, Jean-Marc Baste ${ }^{1}$, Samy Lachkar ${ }^{2,3}$ \\ ${ }^{1}$ Department of General and Thoracic Surgery, University Hospital of Rouen, Rouen, France; ${ }^{2}$ Department of Pulmonology, Thoracic Oncology \\ and Respiratory Intensive Care \& CIC- CRB 1404, University Hospital, Rouen, France; 3 QuantIF- LITIS EA 4108, IRIB, Rouen University, Rouen, \\ France \\ Correspondence to: Pr. Jean-Marc Baste. Department of General and Thoracic Surgery, University Hospital of Rouen, 37 boulevard Gambetta, 76000 \\ Rouen, France. Email: jean-marc.baste@chu-rouen.fr.
}

Received: 01 March 2020; Accepted: 04 June 2020; Published: 05 October 2020.

doi: 10.21037 /jovs-20-71

View this article at: http://dx.doi.org/10.21037/jovs-20-71

In this narrated video (Video 1), we present the role of segmentectomy in the treatment of early stage lung cancer (1-4), lung metastases (5), as well as its diagnostic roles. It shows our multidisciplinary approach in a complete manner in the case of robot-assisted segmentectomy.

We then explore some of the technical challenges related the anatomical variations that we usually encounter, the difficulties in demarcating the intersegmental plane, and how to ensure having sufficient margins around the lesion.

We next underline a shift from open thoracotomy to minimally invasive approaches when it comes to this type of surgery in France. The data of the graph are extracted from Epithor database (6), and it shows the number of segmentectomy, according to the surgical approach from 2009 till June 2019.

The authors think that segmentectomy represent an adapted diagnostic and therapeutic option in the case of solitary lung nodules. Those present as high as $50 \%$ of the lesions in lung screening trials, one must emphasize that the successful management of such lesions decrease lung mortality by more than $20 \%(7,8)$, and that despite advances in imaging-based percutaneous or endobronchial techniques, getting a precise diagnosis can still be very challenging.

Faced by the aforementioned difficulties we developed a multidisciplinary approach to minimally invasive lung segmentectomy $(9,10)$. We first started by creating $3 \mathrm{D}$ reconstructions out of contrast-enhanced CT scans with infra-millimetric slices to study the unique anatomy of the patient, the margins around the lesions, and predict its

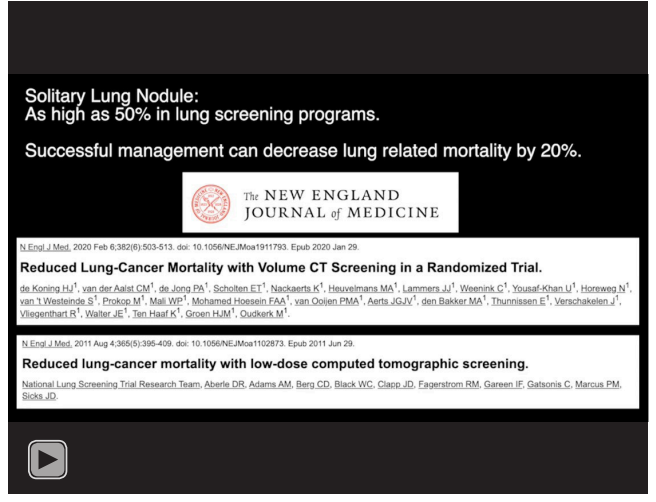

Video 1 Multidisciplinary robot-assisted right S2 segmentectomy.

distance from the intersegmental plane.

To ensure enough margins, we started asking our pulmonology team to do endobronchial dye markings, notably when the lesion seems close to the intersegmental plane on the $3 \mathrm{D}$ reconstruction model. The procedure is done at the operative theater, under general anesthesia minutes before the surgical procedures, thus avoiding repetitive unnecessary general anesthesia and logistic issues.

The teams' technique and initial experience with endobronchial dye marking using virtual bronchoscopy and rEBUS was published in 2018 (11). In a series of 22 patients ( 25 nodules in total) who underwent infra-lobar resections (segmentectomy and wedge resections), the procedure added an average of 10 minutes to the surgical resections, histological diagnosis and free margin resection were obtained in all cases. It's worth noting to say that the 
same operative precision was considered impossible by the surgeon without dye marking in $21 / 25$ cases.

The video includes a whole team approach $(3 \mathrm{D}$ reconstructions, Virtual bronchoscopy, rEBUS double dye marking) in the case of right S2 robot-assisted segmentectomy.

As per our robot-assisted approach, we used 4-arm approach with an assistant port. We used indocyanine green (ICG) to identify the intersegmental plane once all target vessels were identified and stapled. The pulmonologist used double dye endobronchial marking in order to help the surgeon visualize the lesion and its distance from resection plane at all times (during normal and infra-red visions).

The case is that of a 70-year old man who was treated of colorectal cancer in 2015. He was in complete remission till 2019 when on a follow-up CT scan we discovered a left lower lobe $2.5 \mathrm{~cm}$, and a $0.9 \mathrm{~cm}$ right upper lobe lesions.

The patient was in a good shape, and had normal pulmonary function tests. He first underwent left lower lobectomy, final histological analysis showed 2 adjacent lesions, the first was metastatic of colorectal origin, and the second was a primitive lung cancer.

The multidisciplinary meeting decision was to carry out an a right $\mathrm{S} 2$ segmentectomy.

The postoperative course was uneventful, and histological analysis showed a metastatic lesion of colorectal origin.

\section{Acknowledgments}

Funding: None.

\section{Footnote}

Provenance and Peer Review: This article was commissioned by the Guest Editor (Jean-Marc Baste) for the series "Robotic Assisted Thoracic Surgery: Advanced Procedures in Lung and Mediastinum: From Postinduction TTT (immunotherapy) to Sleeve Resection, Complex Segmentectomies and Extended Thymectomy for Myasthenia Gravis" published in Fournal of Visualized Surgery. The article did not undergo external peer review.

Conflicts of Interest: All authors have completed the ICMJE uniform disclosure form (available at https:// jovs.amegroups.com/article/view/10.21037/jovs-20-71/ coif). The series "Robotic Assisted Thoracic Surgery: Advanced procedures in lung and mediastinum: From post-induction TTT (immunotherapy) to sleeve resection,
Complex segmentectomies and Extended Thymectomy for Myasthenia Gravis" was commissioned by the editorial office without any funding or sponsorship. JMB served as the unpaid Guest Editor of the series. JMB reports personal fees from Intuitive Surgery, Medtronic, and Johnson and Johnson, outside the submitted work. SL reports personal fees from Olympus, and Fujifilm, outside the submitted work. The authors have no other conflicts of interest to declare.

Ethical Statement: The authors are accountable for all aspects of the work in ensuring that questions related to the accuracy or integrity of any part of the work are appropriately investigated and resolved. All procedures performed in this study were in accordance the ethical standards of the institutional and/or national research committee(s) and with the Helsinki Declaration (as revised in 2013). The manuscript is waived from patient informed consent according to the ethics committee or institutional review board.

Open Access Statement: This is an Open Access article distributed in accordance with the Creative Commons Attribution-NonCommercial-NoDerivs 4.0 International License (CC BY-NC-ND 4.0), which permits the noncommercial replication and distribution of the article with the strict proviso that no changes or edits are made and the original work is properly cited (including links to both the formal publication through the relevant DOI and the license). See: https://creativecommons.org/licenses/by-nc-nd/4.0/.

\section{References}

1. Lim TY, Park S, Kang CH. A Meta-Analysis Comparing Lobectomy versus Segmentectomy in Stage I Non-Small Cell Lung Cancer. Korean J Thorac Cardiovasc Surg 2019;52:195-204.

2. Bedetti B, Bertolaccini L, Rocco R, et al. Segmentectomy versus lobectomy for stage I non-small cell lung cancer: a systematic review and meta-analysis. J Thorac Dis. 2017;9:1615-23.

3. Suzuki K, Saji H, Aokage K, et al. Comparison of pulmonary segmentectomy and lobectomy: Safety results of a randomized trial. J Thorac Cardiovasc Surg. 2019;158:895-907.

4. Moon MH, Moon YK, Moon SW. Segmentectomy versus lobectomy in early non-small cell lung cancer of $2 \mathrm{~cm}$ or less in size: A population-based study. Respirology 
2018;23:695-703.

5. Berry MF. Role of segmentectomy for pulmonary metastases. Ann Cardiothorac Surg 2014;3:176-82.

6. S.F.C.T.C.V. Société Française de Chirurgie Thoracique et Cardio-Vasculaire [Internet]. Société Française de Chirurgie Thoracique et Cardio-Vasculaire. [cited 2020 Feb 10]. Available online: https://www.sfctcv.org

7. National Lung Screening Trial Research Team, Aberle DR, Adams AM, et al. Reduced lung-cancer mortality with low-dose computed tomographic screening. N Engl J Med 2011;365:395-409.

8. de Koning HJ, van der Aalst CM, de Jong PA, et al. Reduced Lung-Cancer Mortality with Volume CT Screening in a Randomized Trial. N Engl J Med

doi: 10.21037/jovs-20-71

Cite this article as: Sarsam M, Baste JM, Lachkar S. Multidisciplinary approach to minimally invasive lung segmentectomy. J Vis Surg 2020;6:50.
2020;382:503-13.

9. Le Moal J, Peillon C, Dacher JN, et al. Three-dimensional computed tomography reconstruction for operative planning in robotic segmentectomy: a pilot study. J Thorac Dis 2018;10:196-201.

10. Development of a precision multimodal surgical navigation system for lung robotic segmentectomy [Internet]. [cited 2019 Mar 31]. Available online: https://www.ncbi.nlm.nih. gov/pmc/articles/PMC5949399/

11. Lachkar S, Baste JM, Thiberville L, et al. Pleural Dye Marking Using Radial Endobronchial Ultrasound and Virtual Bronchoscopy before Sublobar Pulmonary Resection for Small Peripheral Nodules. Respiration 2018;95:354-61. 